\section{OPEN ACCESS}

Edited by:

Giovanna Schiavoni,

Istituto Superiore di Sanità, Italy

Reviewed by:

Elodie Segura,

Institut Curie, France

Vincenzo Bronte,

University of Verona, Italy

${ }^{*}$ Correspondence:

Marina Cella

mcella@wustl.edu

Specialty section:

This article was submitted to Antigen Presenting Cell Biology,

a section of the journal

Frontiers in Immunology

Received: 29 May 2017 Accepted: 03 October 2017 Published: 25 October 2017

Citation:

Costa ML, Robinette ML, Bugatti M, Longtine MS, Colvin BN, Lantelme E, Vermi W, Colonna M, Nelson DM and Cella M (2017) Two Distinct Myeloid

Subsets at the Term Human

Fetal-Maternal Interface.

Front. Immunol. 8:1357.

doi: 10.3389/fimmu.2017.01357

\title{
Two Distinct Myeloid Subsets at the Term Human Fetal-Maternal Interface
}

\section{Maria Laura Costa ${ }^{1,2}$, Michelle L. Robinette ${ }^{3}$, Mattia Bugatti ${ }^{4}$, Mark S. Longtine', Bryanne N. Colvin ${ }^{1,5}$, Erica Lantelme ${ }^{3}$, William Vermi, ${ }^{3,4}$, Marco Colonna ${ }^{3}$, D. Michael Nelson ${ }^{1}$ and Marina Cella ${ }^{3 *}$}

\begin{abstract}
'Department of Obstetrics and Gynecology, Washington University School of Medicine, St Louis, MO, United States, ${ }^{2}$ Department of Obstetrics and Gynecology, University of Campinas (UNICAMP), Campinas, Brazil, ${ }^{3}$ Department of Pathology and Immunology, Washington University School of Medicine, St Louis, MO, United States, ${ }^{4}$ Department of Molecular and Translational Medicine, Section of Pathology, University of Brescia, Brescia, Italy, ${ }^{5}$ Department of Pediatrics, Washington University School of Medicine, St Louis, MO, United States
\end{abstract}

During pregnancy, immune cells infiltrate the placenta at different stages of fetal development. NK cells and macrophages are the most predominant cell types. These immune cells play pleiotropic roles, as they control spiral artery remodeling to ensure appropriate blood supply and maintain long-term tolerance to a true allograft; yet, they must be able to mount appropriate immune defenses to pathogens that may threaten the fetus. Whether the same cell type accomplishes all these tasks or if there are dedicated subsets remains controversial. Here, we identify and characterize two distinct subsets of myeloid cells that differ in their pro-inflammatory/regulatory capacity. While one subset predominantly produces the immune-modulating cytokine IL-10, the second subset has superior capacity to secrete pro-inflammatory mediators, such as IL-1 $\beta$ and IL-6. The putative regulatory myeloid cells also express high levels of inhibitory receptors and their ligands, including programmed cell death 1 (PD1) ligands. Importantly, a large fraction of CD8 and CD4 cells in normal term human placenta are PD1 positive, suggesting that the PD1/PD1 ligands axis might be critical to maintain tolerance during pregnancy.

Keywords: placenta, antigen-presenting cells, inflammation, tolerance, pregnancy

\section{INTRODUCTION}

Pregnancy is a unique situation during which a truly hemi-allogeneic tissue is well protected from the attack of immune cells that would otherwise have the task of defending "self" from "foreign." Still, maternal cells must be capable of mounting some protective response against bacteria or pathogens that may harm the fetus (1). Therefore, there must be mechanisms in place that tightly regulate the immune landscape and compromise tolerance with defense during pregnancy (2).

The placenta is heavily infiltrated from immune cells throughout pregnancy $(3,4)$. The two most prominent cell types in the placenta are NK cells and macrophages, both of which exert distinct and cooperative functions. Collectively, they are involved in trophoblast invasion, spiral artery remodeling and angiogenesis, removal of apoptotic cells, and protection of the implant from infections $(3,5)$.

To understand how tolerance is enforced in human placenta, we evaluated dendritic cell (DC) representation in this tissue, as DCs are key to maintain peripheral tolerance (6). Surprisingly, we found very few DCs in the basal plate (BP) of normal term human placenta. We instead directed our attention to a subset of $\mathrm{CD} 14^{+} \mathrm{MHC}$ classII ${ }^{\text {high }}$ myeloid cells, most likely macrophages, that based on functional studies and unbiased gene array profiling appear to have tolerogenic and regulatory properties. 


\section{MATERIALS AND METHODS}

\section{Collection of Placental Tissue}

This study was carried out in accordance with the recommendations of Washington University School of Medicine IRB committee with written informed consent from all subjects. All subjects gave written informed consent in accordance with the Declaration of Helsinki. The protocol was approved by the Institutional Review Board of the Washington University School of Medicine, St. Louis, MO, USA. Placentas were obtained from singleton, term (37-40 weeks), uncomplicated gestations delivered by scheduled cesarean section under conduction of anesthesia without labor or delivered vaginally after spontaneous labor, with delivery in $6 \mathrm{~h}$. Placentas were kept at $4^{\circ} \mathrm{C}$ until sampling, with an average time between delivery and sampling of $60 \mathrm{~min}$ (range 30-120 $\mathrm{min}$ ). The placenta was then submitted to random sampling of the BP (maternal-fetal interface), according to recommended procedure for placental sample collection (7). Five to ten en face sections of BP tissue were taken with $\sim 1.5 \mathrm{~cm}^{2}$ surface area and $<0.5 \mathrm{~cm}$ thickness, avoiding areas of visible infarcts or calcifications.

\section{Isolation of Cells from the BP, Flow Cytometry, and Cell Sorting}

Basal plate tissue was finely minced with scissors, digested with collagenase D (1 mg/ml, Roche) for $60 \mathrm{~min}$ at $37^{\circ} \mathrm{C}$ in RPMI medium with $10 \%$ FBS (Hyclone) and pressed through a series of strainers to yield single cells. For identification of DC populations, single cells were stained with a combination of lineage markers (CD3, CD19-PerCP-Cy5.5 eBioscience; CD16, CD56, and CD14PerCP-Cy5.5 Biolegend), CD45-AlexaFluor-700 (Biolegend), HLA-DR-APC (BD), ILT3-PE-Cy7 (Biolegend), ILT1-PE (eBioscience), CD303-FITC (Miltenyi), and CD1c-Brilliant Violet 510 (Biolegend). Cells were acquired on a LSR-Fortessa (BD) and data analyzed with the FlowJo software. For FACS sorting experiments CD14 cells were pre-enriched by magnetic purification (CD14 microbeads, Miltenyi), stained with CD14-FITC (Beckman Coulter) and HLA-DR-APC (BD), and separated on FACS-AriaII (BD). For morphological analysis, $\mathrm{CD} 14^{+} \mathrm{MHCII}^{\text {high }}$ and $\mathrm{CD} 14^{+}$ $\mathrm{MHCII}^{\text {low }}$ cells were immobilized on slides by cytospin and stained with a Hema 3 stain set. Additional antibodies used for flow cytometry analysis: immunoglobulin-like transcript (ILT) 2, CD40, CD54, CD80, CD50, CD89-PE (Beckman Coulter); ILT4APC (eBioscience); ILT5-PE (eBioscience); CXCR4-PE (BD); CD91-eFluor660 (eBioscience); CD206-Brilliant Violet 421; CRACC-PE, CD180-PE, CLEC4A-PE (Biolegend); DQ-FITC (eBioscience); CD9-FITC, CD35-FITC (Beckman Coulter); IDO-PE (eBioscience); mouse IgG1 Control-PE (eBioscience); CLEC4A-PE (Biolegend); CD3-Brilliant Violet 605 (Biolegend); PD1-Brilliant Violet 421 (Biolegend); CD4-APC (eBioscience); CD8-PerCP-Cy5.5 (Biolegend); CD8-APC (eBioscience); and CD4-APC-eFluor-780 (eBioscience).

\section{Statistical Analysis}

Statistics were calculated as indicated in figure legends using the Prism7 software.

\section{Histology}

Formalin-fixed paraffin-embedded tissue blocks used for this study were retrieved from the tissue bank of the Department of Pathology (ASST-Spedali Civili di Brescia, Brescia, Italy). Tissues used for the analysis included normal placental tissue at the first (five cases) and third (ten cases) trimester. Four-micron-thick tissue sections were used for immunohistochemical staining. Primary antibodies included anti-CD14 (1:50, mouse, clone 7, Leica); anti-CD163 (1:50, mouse, clone 10D6, Neomarkers); and anti-HLA-DP,DQ,DR(1:500, mouse, clone CR3/43, DAKO). The reaction was revealed using Novolink Polymer (Leica Microsystems) followed by DAB. Microphtalmia-associated transcription factor (MITF) (1:50, mouse, clone D5, DAKO) was visualized using Mach 4 MR-AP (Biocare Medical), followed by Ferangi Blue (Biocare Medical) as chromogen.

\section{GPNMB Staining by Immunofluorescence}

Cells were FACS sorted and immobilized on slides by cytospin. They were then dried overnight and fixed for $15 \mathrm{~min}$ in methanol at $-20^{\circ} \mathrm{C}$. After blocking for $1 \mathrm{~h}$ at room temperature with PBS containing 5\% FBS, cells were incubated with biotinylated anti-GPNMB (R\&D) (1:100) overnight at $4^{\circ} \mathrm{C}$, followed by $1: 200$ streptavidin-PE (eBioscience) and DRAQ5 1:500 for DNA staining. Images were obtained at $600 \mathrm{X}$ magnification using a Nikon E800 confocal microscope. Three different placentas were sorted and cells placed by cytospin on two slides per placenta, and 10 random pictures of each slide were photographed. Intensity of positive cells for GPNMB per field was quantified using ImageJ software (NIH), by considering the mean gray value within each cell, compared to the average background.

\section{Transcriptome Analysis and Real-time PCR}

For gene expression microarrays, RNA from sorted populations ( $n=4 \mathrm{HLA}-\mathrm{DR}^{\text {high }}$ replicates and $n=3 \mathrm{HLA}-\mathrm{DR}^{\text {low }}$ replicates) was prepared using the RNeasy micro kit (Qiagen), following manufacturer instructions. Gene array data analysis and ingenuity pathway analysis (IPA) were performed as previously described (8). The Affymetrix Human Gene (v.1.0) ST array platform was used (8). Microarrays have been deposited in GEO under accession number GSE104224.

RNA isolation, cDNA generation, and quantitative realtime PCR (qRT-PCR) were done as previously described (9), except using a total reaction volume per well of $10 \mu \mathrm{l}$. To verify amplification of a single product with the appropriate melting temperature, dissociation curves were evaluated for all reactions. RNA expression levels were normalized to parallel reactions with primers specific for GAPDH. The fold increase gene expression in experimental relative to control conditions was determined by utilizing the $2^{-\Delta \Delta \mathrm{Ct}}$ method (10).

Primer list: GPNMB 5'-TAAACCTTGAGTGCCTGCGT, 3'-TGAAATCGTTTGG CGGCATC; UBD 5'-TCTCTGGTTT CTGGCCCCTT, 3'-CGGAACGGACA TGCACACAG; EBI3 5'-AGAGCACATCATCAAGCCCG, 3'-CAGCTCCCTGACGC TTGTAA; CD80 5'-GGGGAAATGTCGCCTCTCTG, 3'-GTGG ATTTAGTTTCACAGCTTGC; IDO1 5'-GATGTGGGCTTTG CTCTACC, 3'-GCTTCCCATTCTCAATCAGC; MITF: 5'-TGT GACTGAACCAACTGGCACTTAC, 3'-TGCTCCGCCTGCTA 
CTCGTT; S100A12: 5'-CACTGCTGGCTTTTTGCTGT, 3'-AA TGCCCCTTCCGAACTGAG; F5: 5'-CACGTGGTTCACTTT CACGG,3'-AATGAACCAGGCAGAAGGGG; andGAPDH:5'-C CTGGTATGACAACGAATTT, 3 '-AGTGAGGGTCTCTCTCT TCC.

\section{Tissue Culture for Cytokine Quantification}

CD14 ${ }^{+}$HLA-DR ${ }^{\text {high }}$ and HLA-DR ${ }^{\text {low }}$ cells were plated in identical numbers ( $10^{5}$ cells/well in duplicate) in $200 \mu$ l of complete RPMI medium in wells of a 96 flat bottom plate. Cells were immediately stimulated with TLR agonists Resiquimod ( $5 \mu \mathrm{g} / \mathrm{ml}$; inVivogen); LPS (100 ng/ml, Ultrapure LPS K12; inVivogen); PolyIC (50 $\mu \mathrm{g} /$ $\mathrm{ml}$; Amersham), Pam3CSK4 (50 ng/ml; inVivogen), and CpG 1826 (6 $\mu \mathrm{g} / \mathrm{ml}$; Qiagen). Supernatants were collected after $18 \mathrm{~h}$ and cytokines quantified by Cytometric Beads Arrays (Human Inflammation, $\mathrm{BD}$ ).

\section{Collection of Term and Pre-Term Placentas for GPNMB Quantification}

A case-control study was also included, under local Ethical approval. Subjects were enrolled and consented in the Women and Infant's Health Specimen Consortium (WHISC). The study was conducted within the Washington University Medical School and Barnes Jewish Hospital in Saint Louis, MO, USA from September 2014 to April 2016. Samples and demographic data collection were de-identified. Placenta was obtained, as previously described in tissue preparation, from singleton gestation of normotensive term ( $\geq 37-41$ weeks) gestations $(n=20)$, term pre-eclampsia $(n=20)$, and pre-term pre-eclampsia with severe features ( $\leq 34$ weeks) $(n=16)$. Pre-eclampsia was diagnosed as new onset of hypertension and either proteinuria or endorgan dysfunction after 20 weeks of gestation in a previously normotensive woman (11). Pre-eclampsia with severe features was defined by the presence of one or more of the following: unrelieved headache, hepatic abnormality, severe blood pressure elevation, thrombocytopenia, progressive renal insufficiency, and pulmonary edema (11). Women with multi-fetal gestations, known medical conditions, including chronic hypertension, diabetes mellitus, renal or collagen vascular disease, and fetal chromosomal abnormalities, were excluded.

Random samples of tissue from the BP were retrieved from delivered placentas, frozen in liquid nitrogen and stored at $-80^{\circ} \mathrm{C}$. RNA was extracted using TRIzol, cDNA prepared from $0.5 \mu \mathrm{g}$ of total RNA and qRT-PCR carried out as described earlier.

\section{RESULTS}

\section{Subsets in Term Placenta Are Poorly Represented Compared to Peripheral Blood}

To investigate the nature and abundance of DCs in the BP of normal term human placenta compared to peripheral blood, we took advantage of our previous staining criteria to identify DC subsets in circulating blood (12). After collagenase extraction, we stained placenta cells with a mixture of CD45, to identify hematopoietic cells, lineage (Lin) markers (CD3, CD19, CD56, CD14, and CD16) to exclude T, B, NK, monocytes, and granulocytes, respectively, and HLA-DR. Among $\mathrm{CD}_{4} 5^{+}$, Lin-negative HLA-DR ${ }^{+}$cells, we distinguished plasmacytoid DCs (pDCs) and myeloid DCs (mDCs) based on the expression of ILTs, ILT3 (CD85K, LILRB4) and ILT1 (CD85H, LILRA2). In blood, ILT3 single positive pDCs homogenously expressed CD303 (BDCA2), while ILT3/ILT1 double positive cells uniformly expressed CD1c (Figure 1A). However, in placenta, DC subsets were less prominent than in blood (Figure 1B). Additionally, the frequency of pDCs and mDCs among Lin-negative HLA-DR ${ }^{+}$cells was significantly lower in the BP tissue (pDCs: $35.9-10.1 \%$; mDCs: $29.2-2.7 \%$ ) than in blood (pDCs: 59.6-30.9\%; mDCs: 50.5-30.5\%) (Figure 1C). Frequencies of pDCs and mDCs in placenta were also significantly lower when percentages of the respective DC subsets were calculated among total $\mathrm{CD} 45^{+}$hematopoietic cells (Figure 1D) (placenta: pDCs: $0.075-0.015 \%$; mDCs: $0.072-0.039 \%$; blood: pDCs: $0.35-0.07 \%$; mDCs: $0.18-0.08 \%$ ).

During these experiments, we noticed a population of $\mathrm{Lin}^{+}$ cells in placenta, which exhibited high expression of HLA-DR and was poorly represented in blood (Figures 1A,B). We reasoned that high expression levels of MHC class II might be linked to antigen processing and presentation. Therefore, we further sought to better characterize this cell subset.

\section{HLA-DR high Cells Are a CD14+ Myeloid Cell Subset That Produces Higher Levels of IL-10 upon TLR Stimulation than HLA- DR ${ }^{\text {low }}$ Cells}

In the attempt to identify the nature of HLA-DR high cells in placenta, we stained each single lineage marker in combination with HLA-DR (not shown). HLA-DR ${ }^{\text {high }}$ cells expressed the lineage marker CD14 (Figure 2A), indicating that they represent a myeloid/monocytic or macrophagic cell subset. HLA-DR ${ }^{\text {high }}$ cells were always less represented than HLA-DR ${ }^{\text {low }}$ cells among $\mathrm{CD} 14^{+}$ myeloid cells (average 17.1-41\% versus 82.9-56.1\%) (Figure 2B). When we FACS sorted the two subsets to high purity and stained them with an equivalent of the classical Wright-Giemsa stain, the morphology of the two subsets was surprisingly similar; both populations exhibited an indented nucleus and a cytoplasm containing many vacuoles, most likely corresponding to lipid droplets (Figure 2C).

Next, we tested the ability of these subsets to respond to TLR stimulation and to produce cytokines. We found that both subsets responded to some extent to TLR2, TLR4, and TLR7 stimulations (Figures 2D,E). However, in general, HLA-DR ${ }^{\text {high }}$ myeloid cells produced more IL-10 in response to both LPS and Resiquimod (Figure 2D), although statistical significance was only reached for LPS stimulation due to donor variation (Figure S1 in Supplementary Material). Conversely HLA-DR ${ }^{\text {low }}$ cells produced significantly more IL- $1 \beta$ and IL-6 in response to LPS (Figure 2D; Figure S1 in Supplementary Material). Both subsets produced TNF- $\alpha$ upon TLR4 engagement, and although more donors yielded higher TNF- $\alpha$ secretion from the HLA-DR ${ }^{\text {low }}$ subset (Figure 2D), statistical significance was not reached (Figure S1 in Supplementary Material). Neither subset responded vigorously to TLR3 or TLR9 stimulation (Figure 2E). 

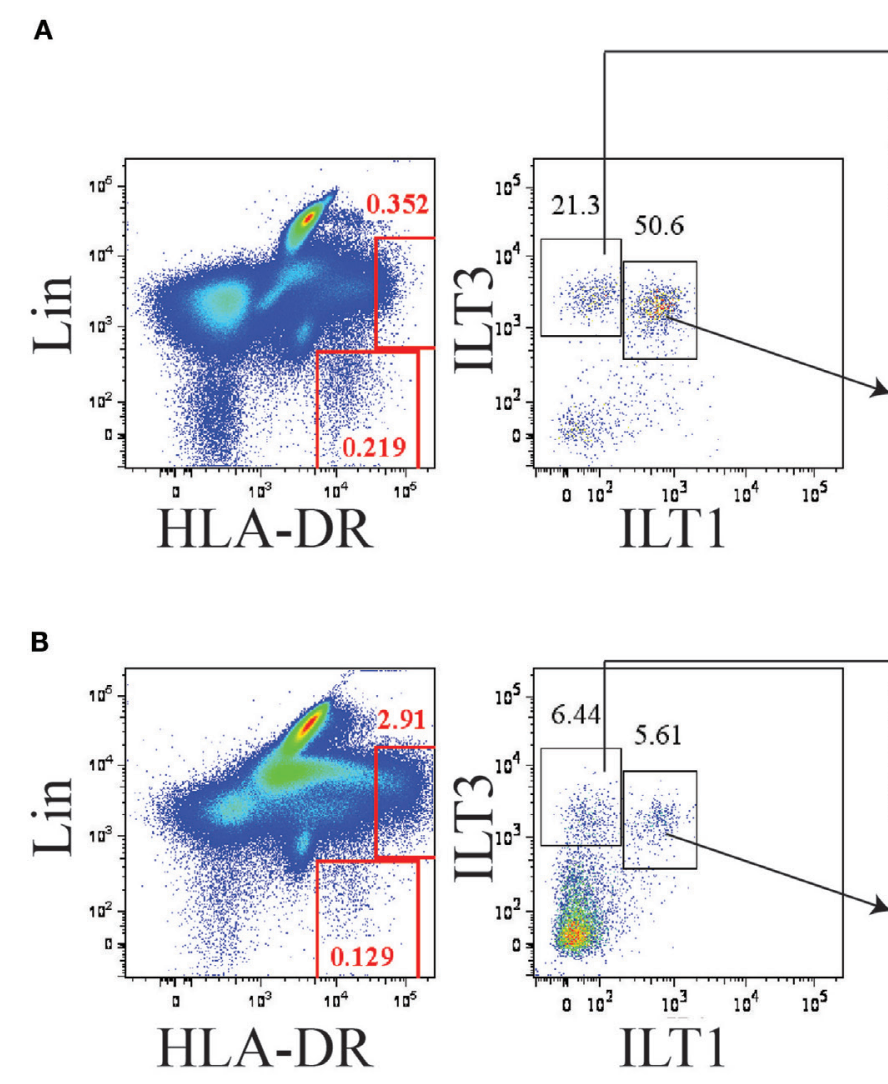
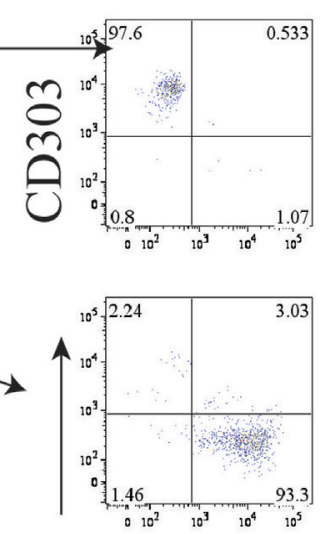

CD1c
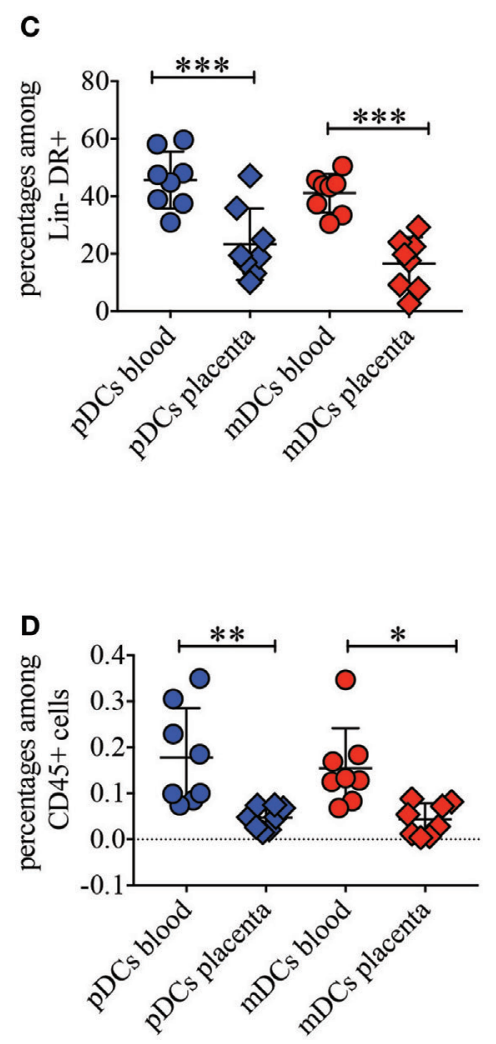

CD1c

FIGURE 1 | Conventional dendritic cell (DC) subsets are poorly represented in basal plate tissue of normal term placentas. (A) Identification of conventional DC subsets in blood and (B) basal plate tissue of normal term placenta. DC subsets were identified within the Lineage negative HLA-DR+ population as ILT3+ILT1plasmacytoid DCs (pDCs), which express BDCA2 (CD303), and as ILT3+ILT1+ myeloid DCs (mDCs), which express CD1c. One representative of eight individual donors for blood and placenta is shown. (C,D) Percentages of pDCs and mDCs in blood and placenta among lineage negative HLA-DR+ (C) or among total CD45+ (D) cells. Significance was calculated by ordinary one-way ANOVA Tukey's multiple comparison test. ${ }^{*} p<0.05$, ${ }^{* *} p<0.005$, and ${ }^{* * *} p<0.0005$.

We conclude that, despite similar morphologies, the two subsets of myeloid cells identified here are prepared to respond to pathogens in different ways. HLA-DR ${ }^{\text {low }}$ cells might predominantly recognize Gram negative bacteria that may invade the placenta and they will produce an inflammatory environment to curb bacteria spreading. HLA-DR ${ }^{\text {high }}$ cells may recognize not only Gram negative bacteria but also ssRNA viruses or, most likely during uncomplicated normal term pregnancy, circulating fetal RNAs. By producing higher levels of IL-10 and lower levels of IL- 6 and IL- $1 \beta$, this cell subset may generate a tolerogenic milieu that avoids fetal rejection.

\section{Unbiased Gene Expression Profile of the Placenta Myeloid Subsets Further Corroborates the Tolerogenic Potential of HLA-DR ${ }^{\text {high }}$ Cells}

In an attempt to better define the nature of the two myeloid subsets identified, we analyzed their gene expression signatures by global gene array profiling. We selected the genes that were significantly differentially expressed greater than two-fold between subsets (Figure 3A). As a control, we also compared expression of these genes with expression in a distant cell type, $\mathrm{CD} 6^{+} \mathrm{NK}$ cells from human peripheral blood. We identified 287 transcripts that were over-expressed in HLA-DR ${ }^{\text {high }}$ cells, while 167 were over-expressed in the HLA-DR ${ }^{\text {low }}$ subset. These genes encode several distinct classes of molecules, including secreted molecules, pattern recognition receptors (PRRs), transcription factors (TFs), cell surface receptors, and proteins involved in cell metabolism or in cell signaling (Figure 3B). Interestingly, HLA-DR ${ }^{\text {high }}$ cells expressed elevated levels of many complement factors, such as $C 1 Q A, C 1 Q B$, and $C 1 Q C, C 2$ and $C 3$, and $C F B$, suggesting that the complement pathway may play a pivotal role in pregnancy. In addition, they expressed high levels of $A P O E$ and $A P O C 2$ and many metabolic genes involved in lipid handling and modification, such as $L P L, S C D, P L T P, F A B P 5$, UGCG, NCEH1, $S G P L 1$, and LIPA. Moreover, HLA-DR ${ }^{\text {high }}$ cells expressed EBI3, also known as p28, a common subunit to the cytokines IL-27 and IL-35, both with known tolerogenic properties. The enzyme IDO1 was also preferentially expressed on HLA-DR ${ }^{\text {high }}$ myeloid 


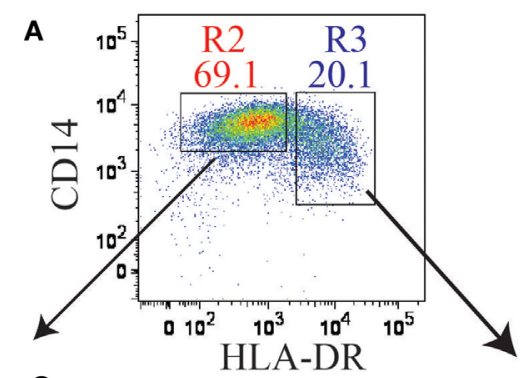

C
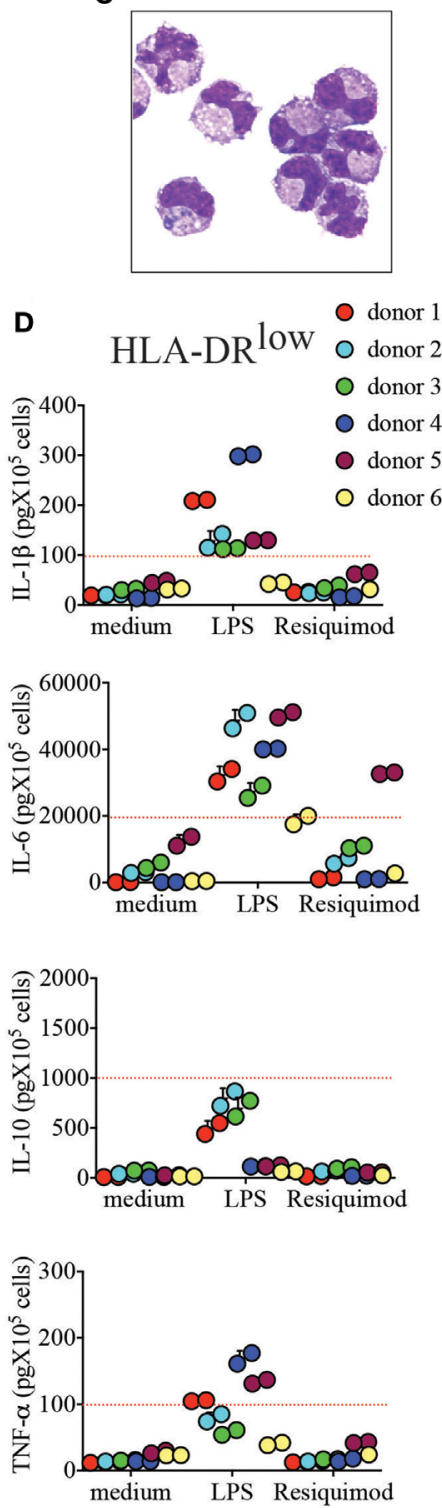
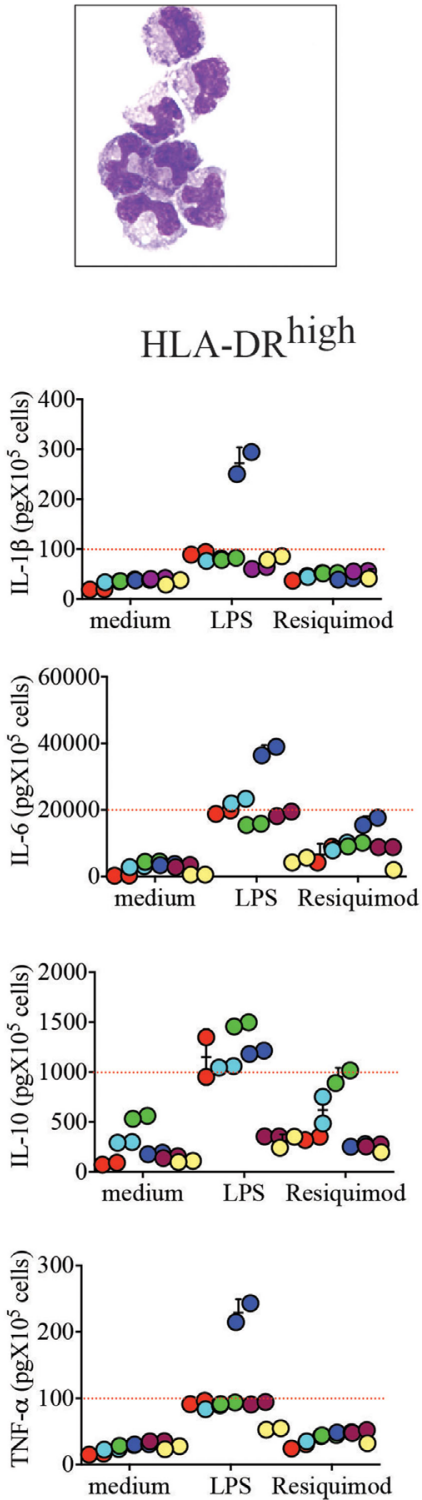

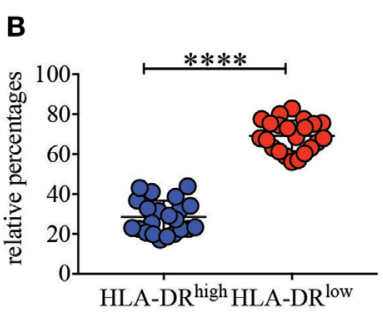

E

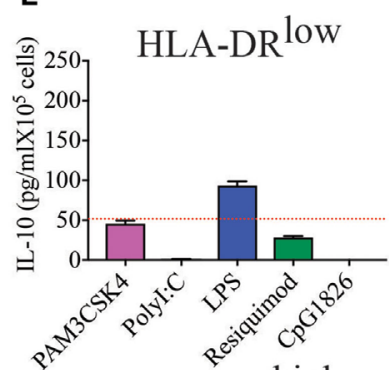

HLA-DR high
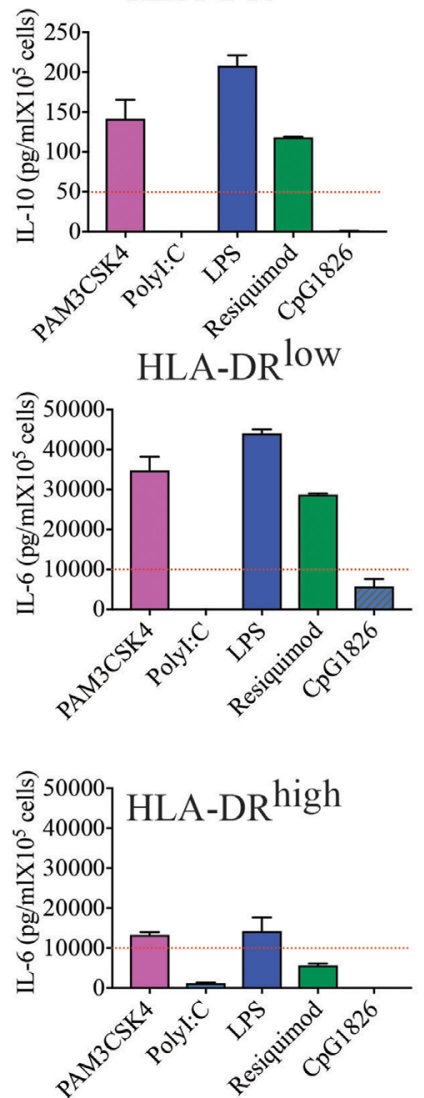

FIGURE 2 | CD14+HLA-DR ${ }^{\text {high }}$ and CD14+HLA-DR low cells, despite similar morphologies, respond differently to toll-like receptor (TLR) stimulation. (A) Representative sorting gate to separate CD14+HLA-DR low and CD14+HLA-DR ${ }^{\text {high }}$ cells. (B) Relative percentages of HLA-DR ${ }^{\text {high }}$ to HLA-DR ${ }^{\text {low }}$ after purification with CD14 microbeads $(n=22) .{ }^{* \star \star \star} p<0.0001$. Significance was calculated by unpaired $T$-test. (C) Cytospin images of the two myeloid cell subsets. (D) Secretion of IL-1 $\beta$, IL-6, IL-10, and TNF- $\alpha$ from HLA-DR ${ }^{\text {low }}$ or HLA-DR ${ }^{\text {high }}$ cells from different donors $(n=6)$. A total of $10^{5}$ cells were either left unstimulated (medium) or stimulated with LPS and resiquimod and cultured for $18 \mathrm{~h}$ prior to cytokine quantifications in supernatants. Each color represents a different donor and assays were run in duplicates. An arbitrary line was drawn to emphasize enhanced IL-1 $\beta$ and IL-6 secretions by HLA-DR ${ }^{\text {low }}$, while HLA-DR ${ }^{\text {high }}$ cells from most donors showed boosted IL-10 secretion.

(E) IL-10 and IL-6 secretions by HLA-DR ${ }^{\text {low }}$ and HLA-DR high placental cells in response to different TLR agonists. One representative donor of 2 tested with PAM3CSK4, Polyl:C, and CpG1826, in addition to LPS and Resiquimod, is shown. An arbitrary line was drawn to emphasize differential cytokine secretion. 


\section{A}

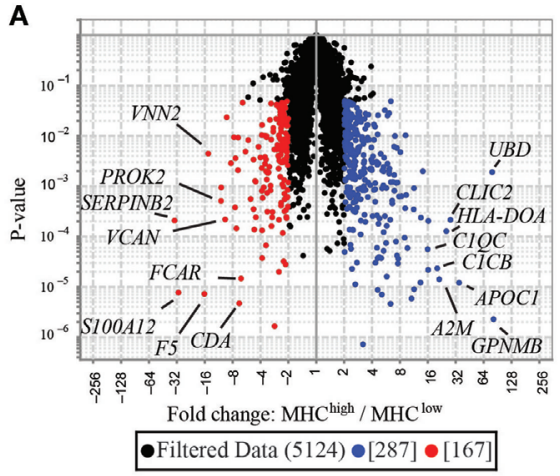

C

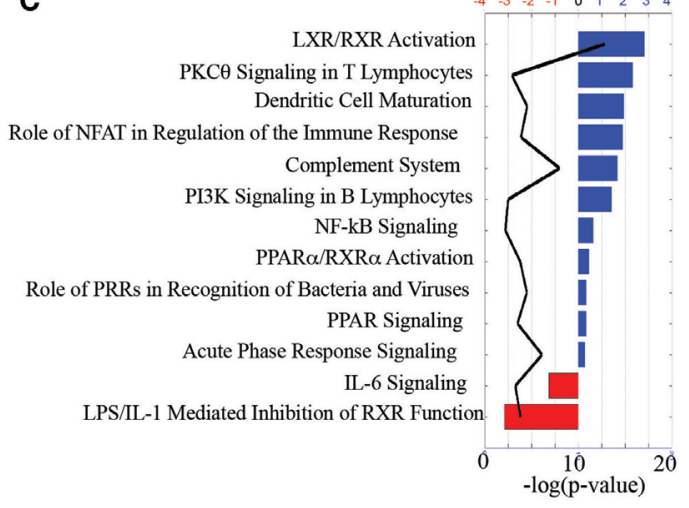

B

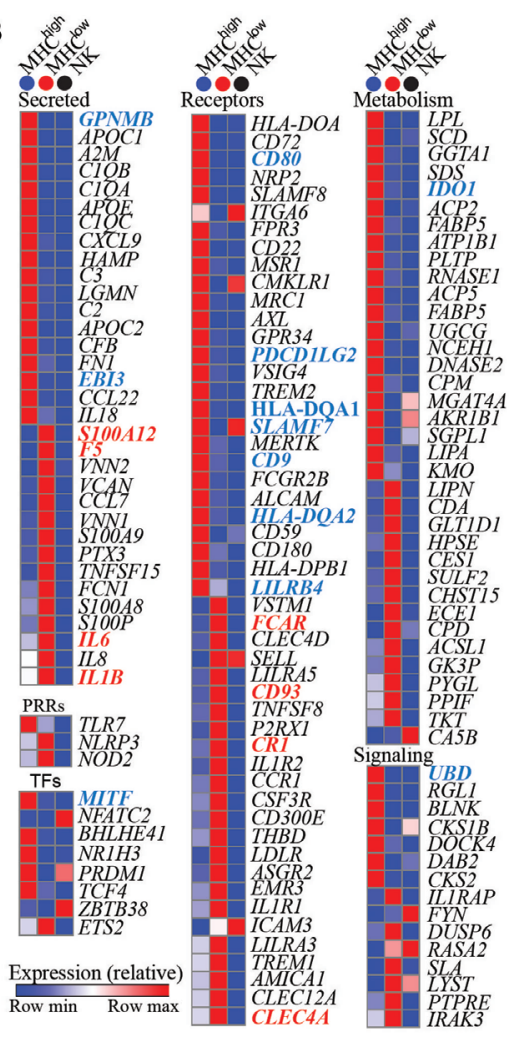

D

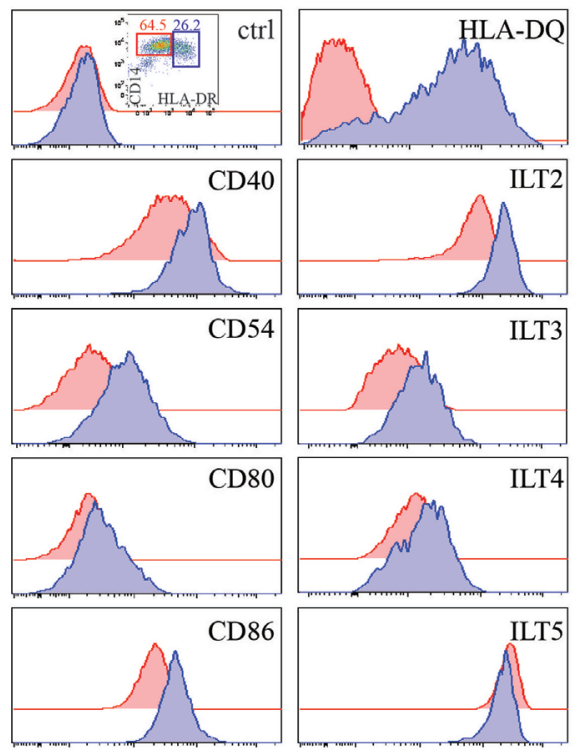

E

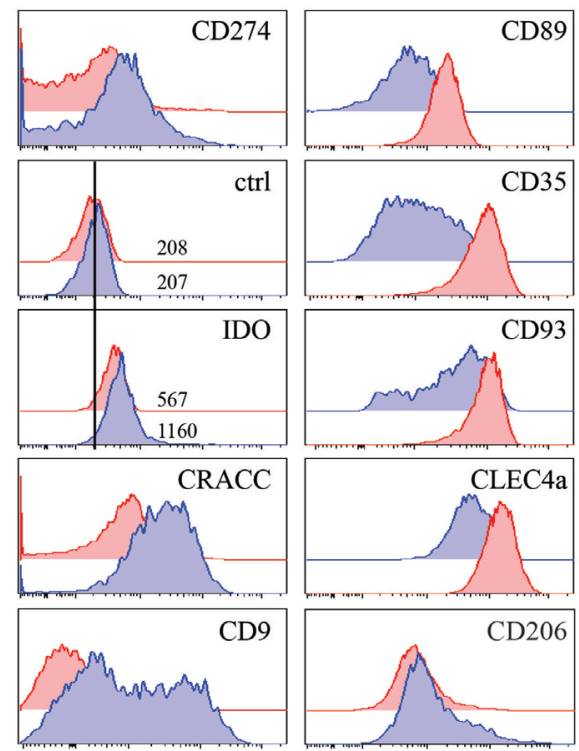

FIGURE 3 | CD14+HLA-DR low and HLA-DR high have unique transcriptional signatures and differentially express cell surface receptors. (A) Volcano plot representing transcripts that are significantly and greater than two-fold expressed by HLA-DR ${ }^{\text {low }}(n=3)$ (red) versus HLA-DR high $(n=4)$ cells (blue). (B) Heatmaps of transcripts differentially expressed between HLA-DR ${ }^{\text {low }}$ and HLA-DR ${ }^{\text {high }}$ cells and categorized as secreted proteins, pattern recognition receptors (PRRs), transcription factors (TFs), cell surface receptors, and molecules involved in metabolism and cell signaling. Transcripts in bold blue (higher expression on HLA-DR high) or red (higher expression in HLA-DR ${ }^{\text {low }}$ indicate genes, which were subsequently validated by protein expression or RT-PCR. Human peripheral blood NK cells were used as comparison, with the rationale that having an innate but distant cell type may maximize our ability to identify genes differentially expressed between the two myeloid cell subsets. (C) Ingenuity pathway analysis networks with highest z-score generated from transcripts differentially expressed between HLA-DR high (blue) and HLA-DR low (red) cells. (D) Protein expression of costimulatory and antigen presenting molecules and inhibitory receptors of the immunoglobulin-like transcript family on HLA-DR high (blue histograms) as compared to HLA-DR ${ }^{\text {low }}$ (red histograms) cells. (E) Increased protein expression of CD274, IDO, CRACC, and CD9 on HLA-DR ${ }^{\text {high }}$ cells and increased expression of CD89, CD35, CD93, and CLEC4A on HLA-DR ${ }^{\text {low }}$ cells. Both subsets express CD206 (mannose receptor) ex vivo. 
cells. This enzyme as well as a second isoform, IDO2, induces cell tolerance by degrading the essential amino acid tryptophan, thus limiting proliferation of antigen stimulated T cells (13). Intriguingly, HLA-DR ${ }^{\text {high }}$ cells also expressed the TF Blimp-1, which was shown to promote and sustain the tolerogenic function of DCs in female mice (14).

Consistent with the trend of HLA-DR ${ }^{\text {high }}$ cells producing higher levels of IL-10 upon Resiquimod stimulation (Figure S1 in Supplementary Material), these cells also expressed higher levels of TLR7. Conversely, HLA-DR ${ }^{\text {low }}$ cells had higher transcripts for genes involved in inflammation, such as the cytokines IL6, IL8, and $I L 1 B$. PRRs that are involved in recognition of bacterial components and inflammasome activation, such as NOD2 and NLRP3 were also more highly expressed. Noteworthy, only a few genes over-expressed on one of the two subsets were also expressed at high levels on peripheral blood NK cells [i.e., CRACC (SLAMF7), CD62L (SELL), ITGA6, and ICAM3].

Next, we performed IPA on genes with significant differences greater than two-fold between HLA-DR ${ }^{\text {high }}$ and HLA-DR ${ }^{\text {low }}$ cells. This analysis indicated that genes enriched in HLA-DR ${ }^{\text {high }}$ cells were linked to LXR/RXR signaling and $\mathrm{PPR} \alpha / \mathrm{RXR} \alpha$ activation, nuclear receptors that mostly bind fatty acids or retinoids and control lipid metabolism. In addition, IPA linked genes enriched in HLA-DR ${ }^{\text {high }}$ cells to DC maturation and to the complement system. On the other hand, genes enriched in HLA-DR ${ }^{\text {low }}$ cells were connected to IL-6 signaling and to LPS/IL-1- mediated inhibition of RXR function, which promotes an inflammatory phenotype in macrophages (Figure 3C).

To functionally validate our data, we selected a few cell surface receptors for which antibodies were available and measured expression of these receptors on the two myeloid subsets. As shown in Figure 3D, costimulatory molecules such as CD40, CD54, CD80, and CD86, in addition to HLA-DQ, were higher in HLA-DR ${ }^{\text {high }}$ cells, in agreement with the DC maturation pathway identified by our IPA. In addition, several inhibitory receptors of the ILT family, such as ILT2 (LILRB1), ILT3 (LILRB4), and ILT4 (LILRB2) had higher expression on HLA-DR ${ }^{\text {high }}$, with ILT5 (LILRB3) being an exception, as it was higher on HLA-DR ${ }^{\text {low }}$ cells. CD274 (PDCD1LG2), a ligand for the inhibitory receptor programmed cell death 1 (PD1), had also higher expression on HLA-DR ${ }^{\text {high }}$, as did the enzyme IDO. Expression of IDO with a commercially available antibody was relatively low and an isotype-matched control was necessary to show a clear shift of the populations (Figure 2E). HLA-DR ${ }^{\text {high }}$ cells also expressed higher level of the CD2 family member CRACC (SLAMF7) (15), which mediate homotypic interactions and inhibit inflammatory cytokines in activated monocytes (16). Moreover, they expressed very high levels of CD9, a tetraspanin induced in human cells by TGF $\beta$ signaling (17), suggesting that HLA-DR ${ }^{\text {high }}$ cells may reside in a TGF $\beta$ rich environment or develop under the influence of TGF $\beta$ (Figure 3E).

In agreement with our gene array data, HLA-DR ${ }^{\text {low }}$ cells expressed higher levels of the IgA-specific Fc receptor CD89; the CR1 CD35; CD93, a receptor which promotes phagocytosis of apoptotic cells and of antibody and complement opsonized particles; and the lectin CLEC4A, also known as DICR (18), which binds carbohydrates, including some that decorate pathogens (19) (Figure 3E). Expression of these receptors supports the idea that this myeloid subset might be involved in bacterial recognition and removal of immunoglobulin or complement opsonized pathogens. Notably, CD206, the mannose receptor, was expressed on both myeloid subsets ex vivo (Figure 3E), suggesting that these cells are tissue specific and not blood derived monocytes, which ex vivo are CD206 negative (20).

To localize the two cell types by immunohistochemistry, we took advantage of our microarray data showing higher expression of MITF on the HLA-DR ${ }^{\text {high }}$ subset. MITF is a TF of the MITF/ TFE family involved in lysosomal biogenesis (21). We examined tissue sections from a set of archival placental tissue from the first and the third trimesters of gestation. As shown in Figure 4, many

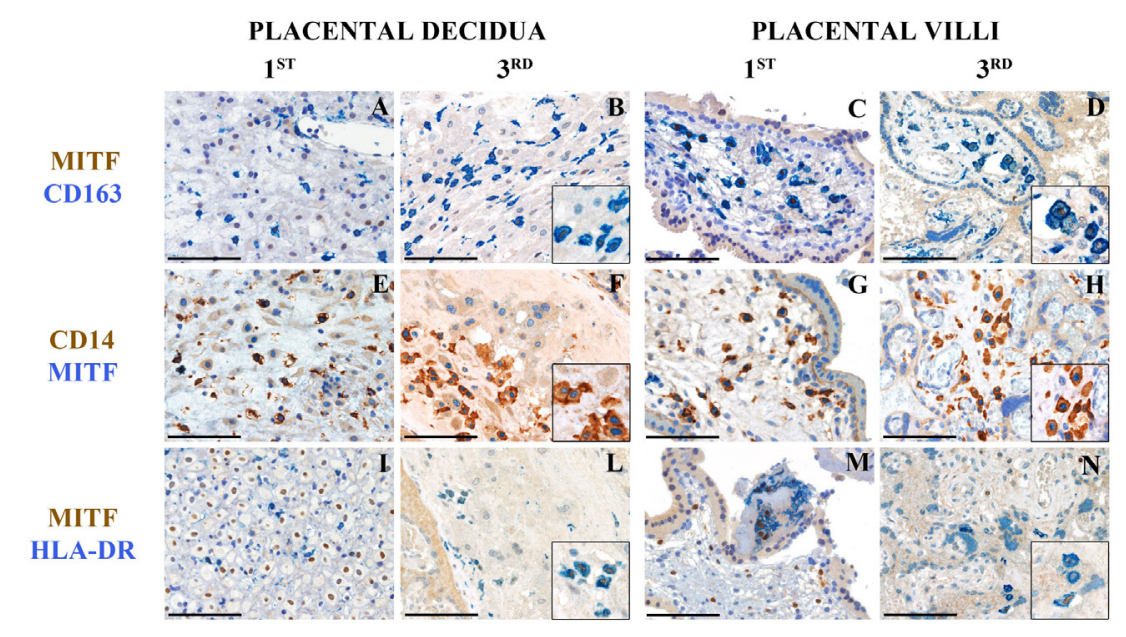

FIGURE 4 | Tissue histology allows identification of MITF+CD14+ cells in human placenta at different stages of gestation. Sections are from first or third trimester normal placenta and stained as labeled. CD163+MIFT+ myeloid are found in placental decidua and placental villi (A-D). MIFT+ myeloid cells that co-express CD14 (E-H) and HLA-DR (I-N) can be identified. Some of these cells are located within small fibrin deposits in the perivillous space (M) and within the decidua (I-L). A variable level of expression of nuclear MIFT+ is also observed in decidual cells at the 1st trimester (I). Magnification 200× (A-N); scale bare 100 $\mu$ m. Inserts magnification 600x. 
cells, at both time points, and, in both placental decidua and villi, stained positive for CD163 and CD14 (Figures 4A-H), two markers, which selectively identify myeloid cells of the monocyte/ macrophage lineage. Some of these cells showed a clear nuclearassociated staining for MITF (Figures $\mathbf{4 B}, \mathbf{D}, \mathbf{F}, \mathbf{H}$, inserts) and seemed inter-dispersed among other $\mathrm{CD}_{163}{ }^{+}$and $\mathrm{CD} 14^{+}$cells that stained negative for MITF, suggesting that the two myeloid cell types here identified did not have a distinct localization but may mingle in the same tissue microenvironment. By double staining with a MHC-class II-specific antibody, we found MHCclass $\mathrm{II}^{+} \mathrm{MITF}^{+}$cells within small fibrin deposits in the perivillar space and within the decidua (Figures 4I-N). However, because of the broad MHC-Class II expression in human on many cell types, we cannot definitively conclude that those cells represent our HLA-DR ${ }^{\text {high }}$ myeloid cells.

To further confirm the differential expression profile of additional genes for which antibodies were not readily available, we performed real-time PCR experiments. Specifically, we aimed to validate $E B I 3, G P N M B$, which is a direct downstream target of $\operatorname{MITF}(22,23), U B D$, the antimicrobial protein S100A12 (24), and F5. CD80, IDO, and MITF were included as positive controls. Indeed, we found that $G P N M B, U B D$, and $E B I 3$ were expressed at significantly higher levels in HLA-DR ${ }^{\text {high }}$ than in HLA-DR ${ }^{\text {low }}$ cells (Figure 5A). We also tested GPNMB expression by immunofluorescent microscopy at the protein level, as this transcript was 80 -fold more expressed on HLA-DR ${ }^{\text {high }}$ than on HLA-DR ${ }^{\text {low }}$. HLA-DR ${ }^{\text {high }}$ showed high expression of GPNM throughout the cytoplasm (Figure 5B), and quantification of the fluorescent signal by ImageJ analysis in the two populations was statistically significant (Figure 5C).

We conclude that a substantial portion of the data generated by our unbiased microarray analysis can be validated at the protein level and that pathways such as complement, apolipoproteins, inhibitory receptors/ligands, and immunoregulatory cytokines/ enzymes are a major signature of HLA-DR ${ }^{\text {high }}$ myeloid cells in the term human placenta from uncomplicated pregnancies.

\section{Decreased GPNMB Expression May Represent a Prognostic Marker for Pregnancy-Associated Diseases}

A precise function for GPNMB (also known as osteoactivin) in immune cells has not been reported. However, this protein, which is also released as soluble form, is highly expressed by some malignancies, including breast cancers and aggressive melanomas. Anti-GPNMB antibodies are currently in clinical trials for cancer $(25,26)$. Because of this link between GPNMB and cancer $(27,28)$, we hypothesized that GPNMB could be involved in maintaining a tolerant environment, which promotes a successful normal term pregnancy. We therefore sought to quantify GPNMB expression by real-time PCR in term placentas without pregnancy complications, placentas from term pregnancies complicated with pre-eclampsia and placentas from pregnancies with pre-term pre-eclampsia with severe features. As shown in Figure 5D, we did not observe significant differences between uncomplicated pregnancies and pregnancies with pre-eclampsia at term. However, despite large variations among samples, we

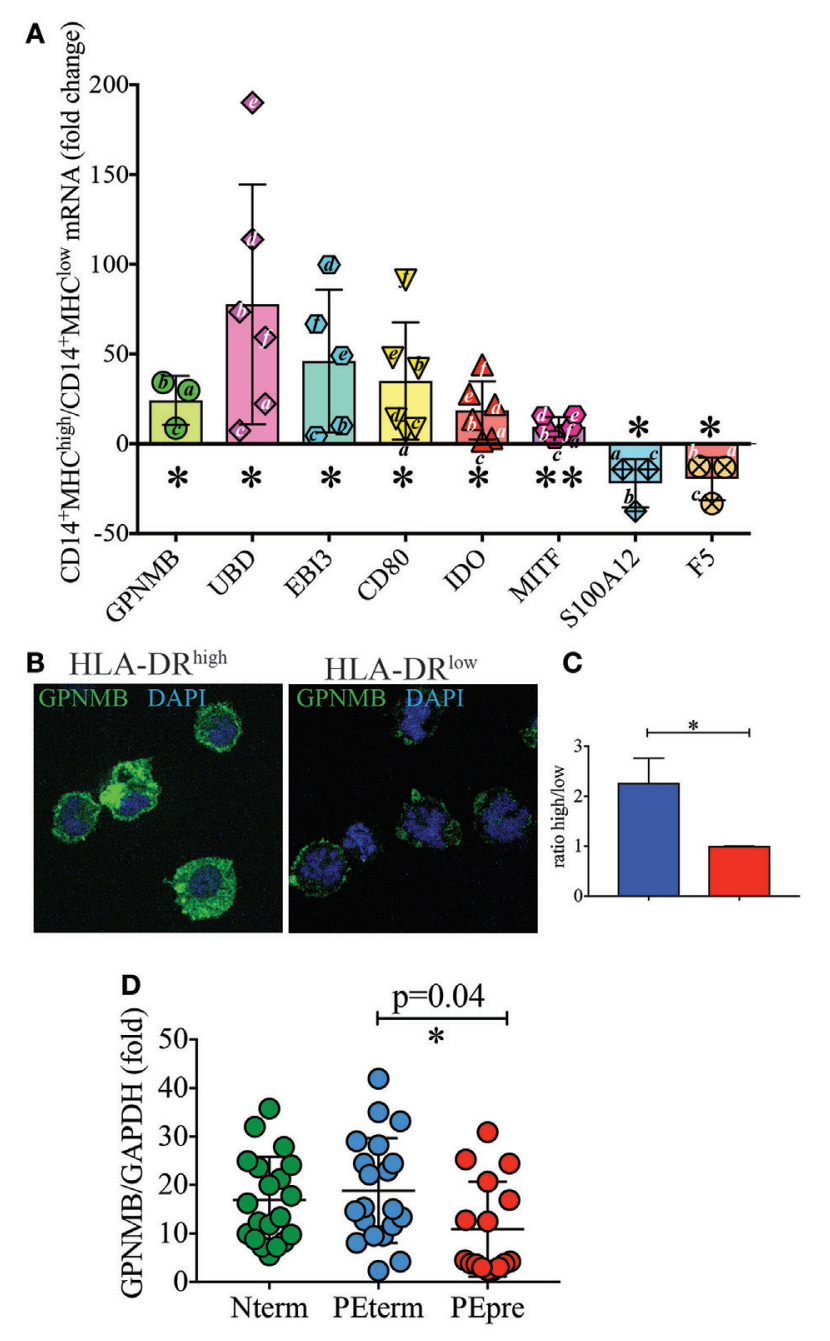

FIGURE 5 | Validation of additional markers on HLA-DR ${ }^{\text {low }}$ and HLA-DR ${ }^{\text {high }}$ cells by RT-PCR and at protein level (A-C). (A) Quantitative RT-PCR analysis of the indicated up- and down-regulated genes in $\mathrm{CD} 14^{+} \mathrm{MHCll}^{\text {high }}$ cells relative to expression in $\mathrm{CD}_{14}{ }^{+} \mathrm{MHCll}^{\text {low }}$ cells, using $\mathrm{GAPDH}$ as a stable reference gene. Data are shown as mean $\pm \mathrm{SE}$, with symbols indicating results from individual placentas. A letter (i.e., a-c) was included within or next to the symbol to indicate matching donors. Statistical significance was determined by Student's $t$-test. ${ }^{\star} p<0.05$ and ${ }^{* *} p<0.005$. (B) Representative GPNMB protein expression levels by immunofluorescence in $\left.\mathrm{CD} 14^{+} \mathrm{MHCl}\right|^{\text {high }}$ and $\mathrm{MHCllow}$ cells. FACS-sorted cells were co-stained for DNA (blue) and GPNMB (green) and the signal intensity of GPNMB determined using confocal microscopy. (C) Relative GPNMB signal intensity for the two cell types $(n=3)$. Statistical significance was determined by Student's $t$-test. ${ }^{*} p<0.05$. (D) Lower expression of GPNMB in placentas from pre-term preeclamptic pregnancies with severe complications. (D) GPNMB expression was determined by RT-PCR in basal plate tissue of placentas from women who had normal term pregnancy (Nterm, $n=20$ ), pre-eclampsia and term delivery (PEterm, $n=20$ ), and pre-eclampsia with severe complications and pre-term delivery (PEpre, $n=16$ ). Values were normalized to GAPDH levels. Statistical significance was determined by ordinary one-way ANOVA.

detected a statistically significant difference in GPNMB expression between placentas of term pre-eclampsia and pre-term pre-eclampsia with severe feature, with the latter group showing reduced GPNMB expression. 


\section{The PD1/PD ligand 1 (PDL1) Pathway Is Highly Represented in Normal Term Placenta}

As PD1 ligands, specifically CD274, had higher expression on HLA-DR ${ }^{\text {high }}$ myeloid cells, we hypothesized that this pathway could contribute to maintenance of tolerance during pregnancy. We therefore investigated expression of PD1 on T cells in normal term placenta. Interestingly, very high percentages of CD4 (41.5-70\%) and CD8 (32.3-79.6\%) T cells expressed high levels of PD1 ex vivo in all the donors tested (Figures 6A,B). To determine whether placenta T cells exclusively express PD1 or whether they also express other inhibitory receptors, we investigated expression of ILT2 (CD85J and LILRB1) which binds HLA-G present on syncytium-trophoblast (29) and also on our myeloid cell subsets (not shown). We found that a few CD4 (1.7-21\%) and some CD8 (9.4-41.8\%) expressed ILT2 (Figure 6C). However, expression of
ILT2 was more variable among donors and never as prominent as PD1 expression.

This findings support the idea that the PD1/PDL1 axis might limit T-cell expansion driven by fetal alloantigen and may play a key role in human pregnancy and in establishing tolerance to the fetal allotransplant.

\section{DISCUSSION}

In this study, we identified two subsets of $\mathrm{CD} 14^{+}$myeloid cells that differ in terms of functional responses to TLR stimulation and cell surface receptors and have a very distinct transcriptional profile. A seminal study previously described two unique human decidual populations based on differential expression of CD11c (30). However, few of the genes identified in our study were also differentially expressed in those two subsets.
A
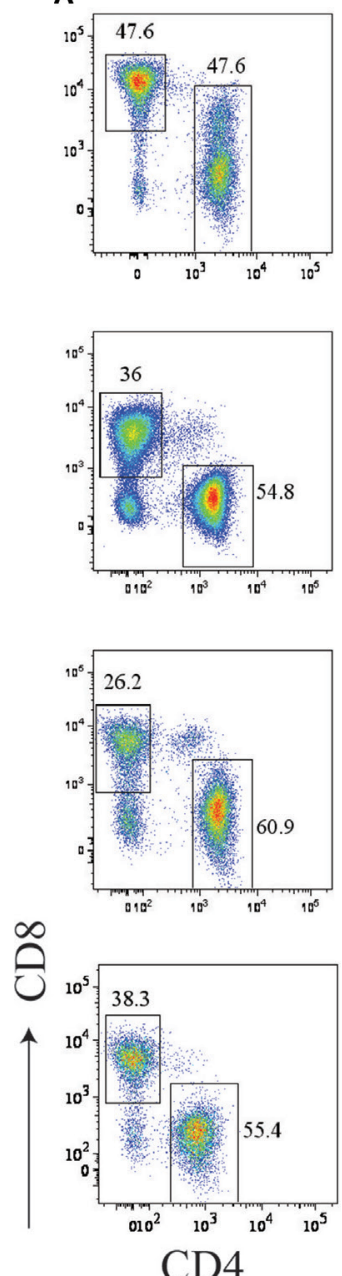
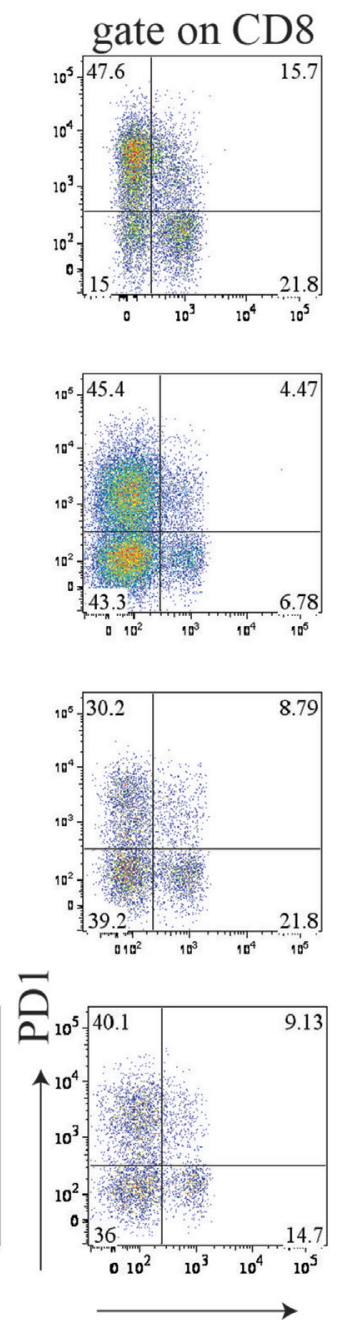
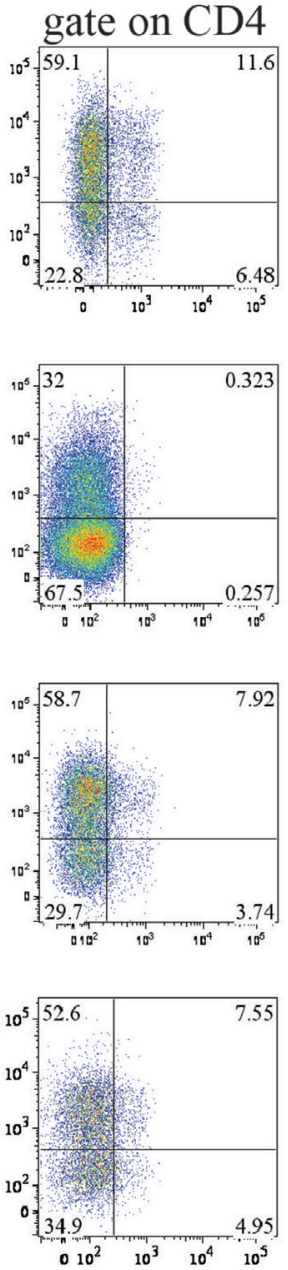

C

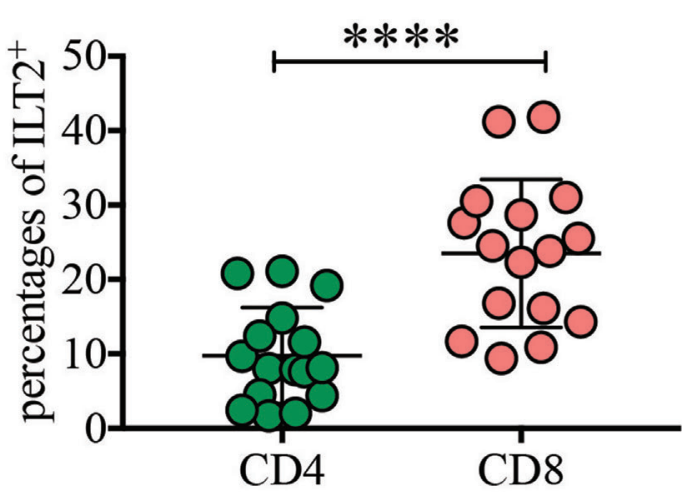

FIGURE 6 | The inhibitory receptor programmed cell death 1 (PD1) is highly expressed among placental T cells. (A) Expression of PD1 and ILT2 (CD85J) on placental CD4 and CD8 T cells. Gate was applied on CD19-CD3 ${ }^{+}$T cells. Four representative donors out of 16 are depicted. (B,C) Percentages of PD1+ (B) and ILT2+ $\mathbf{( C )}$ CD4 or CD8 T cells in different donors $(n=16) .{ }^{\star \star \star \star} p<0.0001$. Significance was calculated by Student's $t$-tests. 
We find that our HLA-DR ${ }^{\text {high }}$ cells produce more IL-10 and express higher level of EBI3, a subunit of IL-27 and IL-35, two members of the IL-12 family of cytokines. Notably, IL-27 and IL-35 have both immunosuppressive and anti-inflammatory properties, though by different mechanisms (31-34). IL-27 is involved in induction of peripheral Foxp $3^{-}$Tregulatory $1(\operatorname{Tr} 1)$ $\mathrm{T}$ cells, which are immunosupressive through the production of IL-10 (35-38). IL-35 instead is produced by conventional Foxp $3^{+}$ Treg, which directly suppresses T-cell proliferation and differentiation (39). B cells can also produce IL-35 (40), which in turn induces other B cells to produce IL-10 $(41,42)$. From our data, it is not clear whether HLA-DR ${ }^{\text {high }}$ cells produce IL-27 or IL-35. However, when we looked in placental BP tissue for induced $\operatorname{Tr} 1$, based on expression of CD49b and LAG-3, as previously reported (43), we did not detect any substantial population of $\operatorname{Tr} 1$ among CD4 T cells. Furthermore, we did not find a significant population of CD4 T cells producing IL-10, when CD4 were maximally stimulated with PMA and Ionomycin (data not shown).

Interestingly, our HLA-DR ${ }^{\text {high }}$ myeloid cells expressed many factors of the complement cascade, as well as APOE and APOC2. It is well established that during pregnancy there is a systemic activation of the complement systems (44) and hyperlipoproteinemia. Increase in Apo-CII in serum is documented in late pregnancy (45). Our data now raise the intriguing possibility that placenta-associated myeloid cells may be a direct source of complement factors and apolipropoteins, whose levels increase in serum during pregnancy.

HLA-DR ${ }^{\text {high }}$ myeloid cells express PD1 ligands and other inhibitory receptors, such as ILTs (46). Importantly, PD1 is highly expressed on a large fraction of CD8 and CD4 cells on all donors tested, suggesting that the PD1/PD1 ligands' axis is positioned to be an important player in establishing and maintaining tolerance in human pregnancy, similar to the role that PD1/PD1 ligands play in tumors $(47,48)$. Accordingly, blockade of PDL1 increases rejection of allogeneic concepti in mouse models (49). High expression of ILT2 and ILT4 on HLA-DR ${ }^{\text {high }}$ cells may also favor CD8 T cells with a Type- 2 cytokine-secreting phenotype (50). In addition, because ILT2 and ILT4 binds to MHC class I, they might bind class I molecules in cis and sequester them from binding to TCR for antigen presentation to CD8 T cells (51).

We show that HLA-DR ${ }^{\text {high }}$ cells produce GPNMB, a soluble mediator expressed by highly aggressive tumors and now a putative target for cancer therapy (28). GPNMB expression on HLA-DR ${ }^{\text {high }}$ cells is likely driven by expression of the TF MITF, given the correlating expression pattern $(22,23)$. Although we did not observe any specific effects of soluble GPNMB in inhibiting proliferation of anti-CD3 stimulated T cells (data not shown), we cannot exclude that GPNMB has indirect immunosuppressive function on other cell types that in turn regulate T-cell proliferation and differentiation. We did observe that GPNMB expression was significantly lower in pre-term pre-eclampsia with severe feature. It has previously been shown that overexpression of GPNMB results in lower levels of pro-inflammatory cytokines, including IL-6 and IL-12 (52), which are elevated in pre-eclampsia (53). In other pathological conditions, such as in acute kidney injury, GPNMB functions as a negative regulator of inflammation by promoting IL-10 and TGF- $\beta$ secretion (54). Therefore, a decrease in GPNMB expression in pre-eclampsia with severe features may represent a sign of worse disease. Alternatively, GPNMB may be upregulated with pregnancy progression. In the future differentiating between these two hypotheses will be important, as GPNMB levels in serum of pregnant women may be used as a potential biomarker to monitor the course and severity of pre-eclampsia.

Despite the fact that our HLA-DR ${ }^{\text {high }}$ subset bears some features of TGF- $\beta$ imprinting, such as higher CD9 expression, we did not observe a specific niche within the decidual tissue or the villi in which $\mathrm{MITF}^{+} \mathrm{CD} 163^{+} \mathrm{CD} 14^{+}$were preferentially located. On the contrary, these cells were interspersed with $\mathrm{MITF}^{-}$ $\mathrm{CD} 163^{+} \mathrm{CD} 14^{+}$cells. This evidence may suggest that either TGF- $\beta$ signaling differs between the two subsets or that one subset may convert to the other under yet unknown circumstances. Additional studies in animal models will be necessary to dissect these hypotheses.

In contrast to HLA-DR ${ }^{\text {high }}$ cells, HLA-DR ${ }^{\text {low }}$ cells seem prepared to mount anti-bacterial response based on their expression of pro-inflammatory factors such as many S100 proteins, IL-6, IL-1 $\beta$, NOD2, and NLRP3. Collectively these factors are well-known drivers of acute inflammation following recognition of bacterial components in part via the inflammasome. This idea is also supported by greater expression of several endocytic receptors by HLA-DR ${ }^{\text {low }}$ cells, such as the C-type lectins DCIR, MCL, and MICL, which may recognize sugar moieties on pathogens. In addition, these cells express IgA receptors, such as CD89 and ASGR2, that may bind IgA opsonized bacteria at the mucosal surfaces. Finally, greater expression of S100A12 by HLA-DR ${ }^{\text {low }}$ cells, confirmed by RT-PCR, supports an antimicrobial role as this protein has large spectrum antibacterial/ antifungal activity due to its zinc binding properties $(24,55)$.

More in depth analysis and animal models will be required to further dissect the function of the two myeloid subsets identified in our study. Nevertheless, our data clearly indicate the existence of at least two subsets of myeloid cells (monocytes/macrophages) in the BP of human normal term placentas, which may differ in their functional properties. One subset seems to exhibit a tolerogenic signature and to utilize immunosuppressive pathways that are often hijacked by tumors to avoid immune surveillance. The second subset seems to have more pro-inflammatory and defense properties and might be involved in protecting the fetus from exogenous pathogens. Single-cell RNA-seq experiments will also be required to verify whether diverse cell types are hidden in each subset, as recently shown for peripheral blood monocytes (56), or whether they represent homogenous populations with a unique transcriptional signature.

\section{ETHICS STATEMENT}

This study was carried out in accordance with the recommendations of Washington University School of Medicine IRB committee with written informed consent from all subjects. All subjects gave written informed consent in accordance with the Declaration of Helsinki. The protocol was approved by the Institutional Review Board of the Washington University School of Medicine, St Louis, MO, USA. 


\section{AUTHOR CONTRIBUTIONS}

MLC, BNC, and DMN were responsible for identifying placentas for collections and clinical information. MLC, EL, and MCe performed sortings and cell culture experiments. MLR performed gene array and IPA. MLC and MSL performed real-time PCR experiments. $\mathrm{MB}$ performed histology tissue stainings. WV supervised specimen collection for tissue histology, instructed histology tissue stainings, and interpreted histology data. DMN, MCo, and MCe conceived and supervised the study. All the authors analyzed and interpreted data. MCe wrote the manuscript with all co-authors contribution.

\section{ACKNOWLEDGMENTS}

We thank the Genome Technology Access Center in the Department of Genetics at Washington University School of Medicine for help with genomic analysis. We thank Susan BossMiller for help with placenta collection.

\section{REFERENCES}

1. Zhang J, Dunk C, Croy AB, Lye SJ. To serve and to protect: the role of decidual innate immune cells on human pregnancy. Cell Tissue Res (2016) 363:249-65. doi:10.1007/s00441-015-2315-4

2. PrabhuDas M, Bonney E, Caron K, Dey S, Erlebacher A, Fazleabas A, et al. Immune mechanisms at the maternal-fetal interface: perspectives and challenges. Nat Immunol (2015) 16:328-34. doi:10.1038/ni.3131

3. Faas MM, de Vos P. Uterine NK cells and macrophages in pregnancy. Placenta (2017) 56:44-52. doi:10.1016/j.placenta.2017.03.001

4. Erlebacher A. Immunology of the maternal-fetal interface. Annu Rev Immunol (2013) 31:387-411. doi:10.1146/annurev-immunol-032712100003

5. Hsu P, Nanan RK. Innate and adaptive immune interactions at the fetal-maternal interface in healthy human pregnancy and pre-eclampsia. Front Immunol (2014) 5:125. doi:10.3389/fimmu.2014.00125

6. Steinman RM, Banchereau J. Taking dendritic cells into medicine. Nature (2007) 449:419-26. doi:10.1038/nature06175

7. Burton GJ, Sebire NJ, Myatt L, Tannetta D, Wang YL, Sadovsky Y, et al. Optimising sample collection for placental research. Placenta (2014) 35:9-22. doi:10.1016/j.placenta.2013.11.005

8. Koues OI, Collins PL, Cella M, Robinette ML, Porter SI, Pyfrom SC, et al. Distinct gene regulatory pathways for human innate versus adaptive lymphoid cells. Cell (2016) 165:1134-46. doi:10.1016/j.cell.2016.04.014

9. Chen B, Zaveri PG, Longtine MS, Nelson DM. N-myc downstream-regulated gene 1 (NDRG1) mediates pomegranate juice protection from apoptosis in hypoxic BeWo cells but not in primary human trophoblasts. Placenta (2015) 36:847-53. doi:10.1016/j.placenta.2015.05.009

10. Schmittgen TD, Livak KJ. Analyzing real-time PCR data by the comparative C(T) method. Nat Protoc (2008) 3:1101-8. doi:10.1038/nprot.2008.73

11. American College of Obstetricians and Gynecologists, Task Force on Hyper tension in Pregnancy. Hypertension in pregnancy. Report of the American College of Obstetricians and Gynecologists' Task Force on Hypertension in Pregnancy. Obstet Gynecol (2013) 122:1122-31.

12. Cella M, Jarrossay D, Facchetti F, Alebardi O, Nakajima H, Lanzavecchia A, et al. Plasmacytoid monocytes migrate to inflamed lymph nodes and produce large amounts of type I interferon. Nat Med (1999) 5:919-23. doi:10.1038/11360

13. Munn DH, Mellor AL. Indoleamine 2,3 dioxygenase and metabolic control of immune responses. Trends Immunol (2013) 34:137-43. doi:10.1016/j. it.2012.10.001

14. Kim SJ, Zou YR, Goldstein J, Reizis B, Diamond B. Tolerogenic function of Blimp-1 in dendritic cells. J Exp Med (2011) 208:2193-9. doi:10.1084/ jem. 20110658

\section{FUNDING}

This work was supported by Grant RO1CA176695 to MCe. MLC was supported by Conselho Nacional de Desenvolvimento Científico e Tecnológico (CNPq), Science Without Borders (200356/2014-3) and by Sao Paulo Research Foundation, (FAPESP - 2014/01925-0). WV is supported by Associazione Italiana per la Ricerca sul Cancro (grant IG 15378).

\section{SUPPLEMENTARY MATERIAL}

The Supplementary Material for this article can be found online at http://www.frontiersin.org/article/10.3389/fimmu.2017.01357/ full\#supplementary-material.

FIGURE S1 | Compiled cytokine secretion data from six different donors to assess statistical significance. Median of duplicate values for each condition was calculated from the six donors in Figure 2A. Significance was calculated by ordinary one-way ANOVA Tukey's multiple comparison test. ${ }^{*} p<0.05$, ${ }^{* *} p<0.005$, and ${ }^{* * * *} p<0.0001$

15. Bouchon A, Cella M, Grierson HL, Cohen JI, Colonna M. Activation of NK cell-mediated cytotoxicity by a SAP-independent receptor of the CD2 family. J Immunol (2001) 167:5517-21. doi:10.4049/jimmunol.167.10.5517

16. Kim JR, Horton NC, Mathew SO, Mathew PA. CS1 (SLAMF7) inhibits production of proinflammatory cytokines by activated monocytes. Inflamm Res (2013) 62:765-72. doi:10.1007/s00011-013-0632-1

17. Keskin DB, Allan DS, Rybalov B, Andzelm MM, Stern JN, Kopcow HD, et al. TGFbeta promotes conversion of CD16+ peripheral blood NK cells into CD16- NK cells with similarities to decidual NK cells. Proc Natl Acad Sci U S A (2007) 104:3378-83. doi:10.1073/pnas.0611098104

18. Kanazawa N, Tashiro K, Inaba K, Miyachi Y. Dendritic cell immunoactivating receptor, a novel C-type lectin immunoreceptor, acts as an activating receptor through association with Fc receptor gamma chain. J Biol Chem (2003) 278:32645-52. doi:10.1074/jbc.M304226200

19. van Kooyk Y, Rabinovich GA. Protein-glycan interactions in the control of innate and adaptive immune responses. Nat Immunol (2008) 9:593-601. doi:10.1038/ni.f.203

20. Sallusto F, Cella M, Danieli C, Lanzavecchia A. Dendritic cells use macropinocytosis and the mannose receptor to concentrate macromolecules in the major histocompatibility complex class II compartment: downregulation by cytokines and bacterial products. J Exp Med (1995) 182:389-400. doi:10.1084/ jem.182.2.389

21. Slade L, Pulinilkunnil T. The MiTF/TFE family of transcription factors: master regulators of organelle signaling, metabolism and stress adaptation. Mol Cancer Res (2017). doi:10.1158/1541-7786.MCR-17-0320

22. Ripoll VM, Meadows NA, Raggatt LJ, Chang MK, Pettit AR, Cassady AI, et al. Microphthalmia transcription factor regulates the expression of the novel osteoclast factor GPNMB. Gene (2008) 413:32-41. doi:10.1016/j. gene.2008.01.014

23. Gutknecht M, Geiger J, Joas S, Dörfel D, Salih HR, Müller MR, et al. The transcription factor MITF is a critical regulator of GPNMB expression in dendritic cells. Cell Commun Signal (2015) 13:19. doi:10.1186/s12964-0150099-5

24. Realegeno S, Kelly-Scumpia KM, Dang AT, Lu J, Teles R, Liu PT, et al S100A12 is part of the antimicrobial network against Mycobacterium leprae in human macrophages. PLoS Pathog (2016) 12:e1005705. doi:10.1371/journal. ppat. 1005705

25. Yardley DA, Weaver R, Melisko ME, Saleh MN, Arena FP, Forero A, et al. EMERGE: a randomized phase II study of the antibody-drug conjugate glembatumumab vedotin in advanced glycoprotein NMB-expressing breast cancer. J Clin Oncol (2015) 33:1609-19. doi:10.1200/JCO.2014.56.2959

26. Naumovski L, Junutula JR. Glembatumumab vedotin, a conjugate of an anti-glycoprotein non-metastatic melanoma protein $\mathrm{B}$ mAb and monomethyl 
auristatin E for the treatment of melanoma and breast cancer. Curr Opin Mol Ther (2010) 12:248-57.

27. Maric G, Rose AA, Annis MG, Siegel PM. Glycoprotein non-metastatic b (GPNMB): a metastatic mediator and emerging therapeutic target in cancer. Onco Targets Ther (2013) 6:839-52. doi:10.2147/OTT.S44906

28. Zhou LT, Liu FY, Li Y, Peng YM, Liu YH, Li J. Gpnmb/osteoactivin, an attractive target in cancer immunotherapy. Neoplasma (2012) 59:1-5. doi:10.4149/ neo_2012_001

29. Ferreira LM, Meissner TB, Tilburgs T, Strominger JL. HLA-G: at the interface of maternal-fetal tolerance. Trends Immunol (2017) 38:272-86. doi:10.1016/j. it.2017.01.009

30. Houser BL, Tilburgs T, Hill J, Nicotra ML, Strominger JL. Two unique human decidual macrophage populations. JImmunol (2011) 186:2633-42. doi:10.4049/jimmunol.1003153

31. Banchereau J, Pascual V, O'Garra A. From IL-2 to IL-37: the expanding spectrum of anti-inflammatory cytokines. Nat Immunol (2012) 13:925-31. doi:10.1038/ni.2406

32. Vignali DA, Kuchroo VK. IL-12 family cytokines: immunological playmakers. Nat Immunol (2012) 13:722-8. doi:10.1038/ni.2366

33. Yoshida H, Hunter CA. The immunobiology of interleukin-27. Annu Rev Immunol (2015) 33:417-43. doi:10.1146/annurev-immunol-032414-112134

34. Sawant DV, Hamilton K, Vignali DA. Interleukin-35: expanding its job profile. J Interferon Cytokine Res (2015) 35:499-512. doi:10.1089/jir.2015.0015

35. Stumhofer JS, Silver JS, Laurence A, Porrett PM, Harris TH, Turka LA, et al. Interleukins 27 and 6 induce STAT3-mediated T cell production of interleukin 10. Nat Immunol (2007) 8:1363-71. doi:10.1038/ni1537

36. Pot C, Jin H, Awasthi A, Liu SM, Lai CY, Madan R, et al. Cutting edge: IL-27 induces the transcription factor c-Maf, cytokine IL-21, and the costimulatory receptor ICOS that coordinately act together to promote differentiation of IL-10-producing Tr1 cells. JImmunol (2009) 183:797-801. doi:10.4049/ jimmunol.0901233

37. Apetoh L, Quintana FJ, Pot C, Joller N, Xiao S, Kumar D, et al. The aryl hydrocarbon receptor interacts with c-Maf to promote the differentiation of type 1 regulatory T cells induced by IL-27. Nat Immunol (2010) 11:854-61. doi:10.1038/ni.1912

38. Hall AO, Beiting DP, Tato C, John B, Oldenhove G, Lombana CG, et al. The cytokines interleukin 27 and interferon-gamma promote distinct Treg cell populations required to limit infection-induced pathology. Immunity (2012) 37:511-23. doi:10.1016/j.immuni.2012.06.014

39. Collison LW, Workman CJ, Kuo TT, Boyd K, Wang Y, Vignali KM, et al. The inhibitory cytokine IL-35 contributes to regulatory T-cell function. Nature (2007) 450:566-9. doi:10.1038/nature06306

40. Shen P, Roch T, Lampropoulou V, O'Connor RA, Stervbo U, Hilgenberg E, et al. IL-35-producing B cells are critical regulators of immunity during autoimmune and infectious diseases. Nature (2014) 507:366-70. doi:10.1038/ nature 12979

41. Yoshizaki A, Miyagaki T, DiLillo DJ, Matsushita T, Horikawa M, Kountikov EI, et al. Regulatory B cells control T-cell autoimmunity through IL-21-dependent cognate interactions. Nature (2012) 491:264-8. doi:10.1038/nature11501

42. Tedder TF, Leonard WJ. Autoimmunity: regulatory B cells - IL-35 and IL-21 regulate the regulators. Nat Rev Rheumatol (2014) 10:452-3. doi:10.1038/ nrrheum.2014.95

43. Gagliani N, Magnani CF, Huber S, Gianolini ME, Pala M, Licona-Limon $\mathrm{P}$, et al. Coexpression of CD49b and LAG-3 identifies human and mouse T regulatory type 1 cells. Nat Med (2013) 19:739-46. doi:10.1038/nm.3179
44. Richani K, Soto E, Romero R, Espinoza J, Chaiworapongsa T, Nien JK, et al. Normal pregnancy is characterized by systemic activation of the complement system. J Matern Fetal Neonatal Med (2005) 17:239-45. doi:10.1080/14767050500072722

45. Flood-Nichols SK, Tinnemore D, Wingerd MA, Abu-Alya AI, Napolitano PG, Stallings JD, et al. Longitudinal analysis of maternal plasma apolipoproteins in pregnancy: a targeted proteomics approach. Mol Cell Proteomics (2013) 12:55-64. doi:10.1074/mcp.M112.018192

46. Cella M, Nakajima H, Facchetti F, Hoffmann T, Colonna M. ILT receptors at the interface between lymphoid and myeloid cells. Curr Top Microbiol Immunol (2000) 251:161-6.

47. Pardoll DM. The blockade of immune checkpoints in cancer immunotherapy. Nat Rev Cancer (2012) 12:252-64. doi:10.1038/nrc3239

48. Sharma P, Allison JP. Immune checkpoint targeting in cancer therapy: toward combination strategies with curative potential. Cell (2015) 161:205-14 doi:10.1016/j.cell.2015.03.030

49. Guleria I, Khosroshahi A, Ansari MJ, Habicht A, Azuma M, Yagita H, et al. A critical role for the programmed death ligand 1 in fetomaternal tolerance. J Exp Med (2005) 202:231-7. doi:10.1084/jem.20050019

50. Banchereau J, Zurawski S, Thompson-Snipes L, Blanck JP, Clayton S, Munk A, et al. Immunoglobulin-like transcript receptors on human dermal CD14+ dendritic cells act as a CD8-antagonist to control cytotoxic T cell priming. Proc Natl Acad Sci U S A (2012) 109:18885-90. doi:10.1073/pnas.1205785109

51. Held W, Mariuzza RA. Cis interactions of immunoreceptors with MHC and non-MHC ligands. Nat Rev Immunol (2008) 8:269-78. doi:10.1038/nri2278

52. Ripoll VM, Irvine KM, Ravasi T, Sweet MJ, Hume DA. Gpnmb is induced in macrophages by IFN-gamma and lipopolysaccharide and acts as a feedback regulator of proinflammatory responses. J Immunol (2007) 178:6557-66. doi:10.4049/jimmunol.178.10.6557

53. Das UN. Cytokines, angiogenic, and antiangiogenic factors and bioactive lipids in preeclampsia. Nutrition (2015) 31:1083-95. doi:10.1016/j.nut.2015. 03.013

54. Zhou L, Zhuo H, Ouyang H, Liu Y, Yuan F, Sun L, et al. Glycoprotein non-metastatic melanoma protein $\mathrm{b}$ (Gpnmb) is highly expressed in macrophages of acute injured kidney and promotes M2 macrophages polarization. Cell Immunol (2017) 316:53-60. doi:10.1016/j.cellimm.2017.03.006

55. Zackular JP, Chazin WJ, Skaar EP. Nutritional immunity: S100 proteins at the host-pathogen interface. J Biol Chem (2015) 290:18991-8. doi:10.1074/jbc. R115.645085

56. Villani AC, Satija R, Reynolds G, Sarkizova S, Shekhar K, Fletcher J, et al. Single-cell RNA-seq reveals new types of human blood dendritic cells, monocytes, and progenitors. Science (2017) 356:6335. doi:10.1126/science. aah4573

Conflict of Interest Statement: The authors declare that the research was conducted in the absence of any commercial or financial relationships that could be construed as a potential conflict of interest.

Copyright (c) 2017 Costa, Robinette, Bugatti, Longtine, Colvin, Lantelme, Vermi, Colonna, Nelson and Cella. This is an open-access article distributed under the terms of the Creative Commons Attribution License (CC BY). The use, distribution or reproduction in other forums is permitted, provided the original author(s) or licensor are credited and that the original publication in this journal is cited, in accordance with accepted academic practice. No use, distribution or reproduction is permitted which does not comply with these terms. 